\title{
Alignment and variation in managerial and professional perceptions of purpose, leadership roles and outcomes in a healthcare organisation's change programme
}

\author{
Stiofán de Búrca \\ Health Systems Research Centre, Department of Sociology, University of Limerick
}

The aim of this paper is to clarify determinants of leadership effectiveness by examining key points of agreement and difference in managers' and professionals' expectations and experiences of organisational change in a healthcare organisation. This is a reflexive qualitative case study carried out by an insider. A pluralist approach to methods (including interviews and records of meetings), and to managerial and professional levels and service settings, is used. Textual data is analysed using a modified grounded theory approach. Six data groups, comprising 24 data sets, are processed through a short version paradigmatic analysis to yield an analytic text from the coded data to provide a narrative based on participants' observations and responses. While there is agreement on positive organisational and service outcomes that reflect the leadership style and the approach to change, management and professional domains have different views regarding quality, actions, leadership constructs definitions and prototypes. There are, however, matched expectations and indications regarding primary attributes of leadership. Senior managers' systemic view of leadership and quality, and middle managers' and professionals' more domain and role specific views, connect, although they are varied in their role contexts. Intra-domain tensions contrast with no evidence of traditional medicine - management conflict. The key domain alignments are in a shared purpose, leadership style and approach, and sense of being valued.

\section{Introduction}

Liz is at rest now, and her vibrant spirit hovers where once we saw that bright charming humanity that inspired us. Her external agency in early efforts in reforming mental health care was both instrumental and influential in re-professionalising institutionalised carers in normalising themselves and their charges in more humane settings. From keeper to therapist and holistic enabler she changed them, and even touched the souls of their

Address correspondence to: Stiofán de Búrca, Department of Sociology, University of Limerick, Limerick, Republic of Ireland. Email: stiofan.deburca@ul.ie 
bureaucratic overseers. Our exposure to this gifted philosopher, analyst, and influencer of the heart, mind and spirit fuelled our drive to contribute to the vulnerable whom she cherished. Her spirit rekindles us in pursuing her purposeful enquiries, and informs this current enquiry into healthcare leadership and management.

There has been a paucity of research on theories of change in healthcare settings (Pettigrew, Ferlie, \& McKee, 1992). Of critical interest in the model health service change that Pettigrew et al. (1992) proposed was the availability of key people leading change, and the exercise of that leadership in a subtle and pluralist fashion. They emphasise 'leading change' as against 'leadership' to denote the collective complexity and multifaceted aspect of leading change (p. 276). Their view is consistent with others who have argued that control has limited utility where bureaucratic and collegiate organisations co-exist in an uneasy mutual interdependence (Mintzberg, 1983; Yuk1, 1998).

As well as leading extremely complex organisations, healthcare managers have been subjected to waves of reforms and practices associated with new public management (Flynn \& Strehl, 1996). It has been argued that the application of such managerial practices to the management of professionals has reduced the autonomy of professionals and restricted the centre to strategy, policy, and prioritisation (Ferlie, Ashbourner, Fitzgerald, \& Pettigrew, 1996). This relationship between managers and professionals is central to the current study.

\section{Domain conflict in hospital management}

Managers and professionals occupy influential domains, particularly in hospital contexts. Their different orientations and arrangements tend to separate and disconnect them by promoting separate identities. This prevents the development of a common vision, and leads to the destruction of any sense of coherence and connectedness (Edmondstone, 1986). Within the domains there are also practice status and hierarchical tensions. Medicine, as the archetypal profession, has strong socialisation and occupational influences (Johnson, 1985), but weak organisational socialisation (Manning, 1977). This can result in service delivery being organised to accommodate professional rather than public interests (Saltman \& Figueras, 1997).

Nurses among others are categorised as semi-professional as they are supervised and applied when compared with the more theoretically influenced and autonomous work of the professions (Etzioni, 1969). As such, they are more likely to succumb to managerial influences (Lorentzon, 1990) and defer to doctors. They are, however, described as preservers of order around the patient treatment regime, integrators of the patient care system, and facilitators of the efforts of the multi-disciplinary team (Taylor \& Taylor, 1994).

The difference between managers and professionals may be understood in Gouldner's (1957/1958) terms as 'locals' and 'cosmopolitans', where managerial conformity is the result of embeddedness in the routines of bureaucratic life, and is subordinate to the organisation's needs and the professional's need, for the organisation is perceived strictly in terms of its support for professional activity. Professionals look to the professional college to provide recognition. Domains Theory (Kouse \& Mico, 1979) clarifies the three domain orientations in human service systems. The policy domain is responsible to the electorate; management addresses corporate accountability; and the 
professionals seek the best services for clients. Smith (1984) has suggested that their different value sets can create tenuous antagonistic relationships and render irrelevant the management principles of hierarchy and control.

Clinicians claim that their involvement in management is constrained by time and negative peer pressure (Hearing et al., 1999). Their more recent adoption of quasimanagerial roles is interpreted by some as an acceptance of managerial values aligned with their own concerns (Sheaf, 2000), the re-professionalisation of expertise (Thorne, 2002), or, being bureaucratised by accepting responsibility in clinical directorates (Kitchener, 2000). There are some hybrid physician/manager successes such as higher performance standards and leadership skills, being attributed to physicians (as against non-physicians) in leader positions, and also when they are involved at a high level of organisational decision making (Shipper, Pearson, \& Singer, 1998; Shortell, Morrisson, \& Robbins, 1995). The emergence of hybridisation points to domain overlap in an alignment of professional and organisational interests and the multi-disciplinary ownership of executive teams led by dually competent clinicians.

In the context of sometimes conflicting and changing positions, and of the continuous change process in health service management and delivery, this study focuses on managers' and medical professionals' perceptions of their respective roles in the context of attempts to change a health service to make it more people-centred. This article reports part of a larger study of management of this change process, focusing specifically on those contrasting role perceptions that may affect the organisation's tendency to change and/or its leadership effectiveness.

\section{Setting}

\section{Research methodology}

The study was undertaken in an Irish Regional Health Board during a period of significant organisational change in both this board and in the health services generally. The Health Board in question was a complex service system that was geographically dispersed and provided a wide range of health and personal social services through many disciplines and agencies. Its variety of services and structures included a Regional Acute Hospital, and several institutional and community services. Certain aspects of the inherited order, such as an inadequate involvement of the professions, particularly doctors, in organisational processes and a centralist organisational style, were challenges for the new corporate management.

\section{Method}

The choice of phenomenon to be studied suggested that a qualitative case study strategy would provide the most appropriate methodology (Denzin \& Lincoln, 1998). An opportunistic case study involving participant observation was undertaken. Participant observation is seen as the source of authoritative interpretation in ethnographic field research (Clifford, 1983), and is seen as a useful research strategy for studying professional practice in psychology (e.g., Etherington, 2004). There are also precedents in organisational research where the researcher held a responsible functional role, and where that duality (manager and researcher) reframed work as a learning laboratory (Coghlan \& Brannick, 2001; Homa, 1998; Krim, 1988). 
In this study, the CEO of the Health Board is also the researcher. The dual roles of CEO and researcher present both challenges and opportunities. As a daily 'participant observer' in a 'complete member role' the researcher has extensive access and insight to the field of enquiry. Potentially rewarding research topics are often inaccessible as organisations are unwilling to provide access to sensitive and traumatic events. In this study, familiarity with the organisation facilitates sampling and access within availability and time constraints for respondents and the researcher. In addition to primary and secondary access to actors, events, and archives, researchers in dual roles also have preunderstanding of the valuable knowledge about the cultures and informal structures of their organisations. Coghlan and Brannick (2001) state that insider researchers use preunderstanding of organisational knowledge and studies for personal and professional development. In second person research they work on practical issues of concern to the organisation in collaboration with colleagues and others. In third person research, understanding and theory are generated and extrapolated from the experience. The opportunistic adoption of projects already underway in an organisation (as in the change programme reported here) is undertaken by various professions for their own research project (Coghlan \& Brannick, 2001).

Ethical issues arise from the nature of the relationship between the researcher, the organisation, and the respondents. In the final analysis "ethical fieldwork turns on the moral sense and integrity of the researcher negotiating the social contract which leads his subjects to explore their lives" (Dingwall, 1980, p. 885). In this study, the $\mathrm{CEO}$ as management researcher recognises that ethical behaviour in dual roles benefits from reflexivity and reflectivity. Authentic relationships with peers and subordinates as participants in the research are based on mutual trust and honesty. One's own attitude, behaviour, and management style in interpersonal and organisational relationships are critical factors in the issues under investigation. Ethics, according to Coghlan and Brannick (2001), involve not only not deceiving or doing harm, but being true to the process. Over time, this duality is accepted as another dimension of a multi-faceted role.

However, the members of the organisation may not regard their own manager as someone with whom they can extend full frankness. Moreover, the researcher-manager may not be able to be objective in analysing others' accounts of his and related roles and behaviours. The methods adopted in this thesis were able, to an unusual degree, to rely on the organisation's collegial perspectives, which were shared by many of the participants who were also senior managers. This may not always be the case.

A modified grounded theory approach (Partington, 2000), using the general principles set out in Strauss and Corbin's (1990) paradigmatic analysis, was used in this study to provide necessary rigour to the process of data collection and analysis. It included simultaneous data collection and analysis using constant comparative analysis and theoretical sampling in various organisational levels and settings. Using multiple methods of enquiry (multi-disciplinary focus group, semi-structured interviews and a survey and document analysis), six data groups which encompassed 24 data-sets were generated. Five of them were qualitative groups. 


\section{Procedure}

Data collection and analysis took place over a period of two and a half years to capture a sense of what was changing. Focus groups, review sessions, and semi-structured interviews were conducted initially with corporate line and function managers and general managers. This was followed by semi-structured interviews with senior clinicians and directors of nursing from various specialities and then focus groups with ten multidisciplinary service groups over an extended period. Semi-structured questionnaires were used with middle managers prior to the end of the first year, and finally with a variety of managers (e.g., general, functional, directors of services, care group managers, and heads of discipline). Thus, corporate, general, and mid-level management, as the managerial domain, had correspondence with senior clinicians and nursing, heads of discipline and multi-disciplinary professional groups as the professional domain. This enquiry spread over various managerial and professional levels in corporate and local acute and non-acute care in various service locations.

Interviews were transcribed and transcripts analysed using line coding, followed by focused coding. Categories were generated through these codes by comparison between data, incidents and contexts and concepts. Memo writing helped to identify patterns and clarify categories, and lead to theoretical sampling. The data groups were processed sequentially and iteratively to yield the overarching categories and properties. They provided the basis of an analytic framework and structure for the analytic text.

\section{Making change}

\section{Results}

The need to change was stimulated by external factors and an internal awareness that to achieve its purpose, the organisation had to move from a directive style and traditional administrative orientation, which was reported to have alienated staff and inhibited development. The overarching aim of quality of care had a population dimension, which was attributed to senior managers, and a professional practice dimension. The enabling objectives were identified as the development and diffusion of leadership throughout the organisation, improvement in relationships, ownership, the practice and performance of management, and relevant and effective structures.

The common objective was to gain organisation-wide commitment to the new vision and values. Managers worked hard on this. For example, an assistant CEO initiated workshops for care group managers, and communicated with each group to achieve a sense of clarity and thinking on the desired outcomes. General managers conducted regional meetings with staff representatives, "communicated change via structures and grapevine ... a process of consultation which involved younger Consultants" and availed of staff meetings "to listen and take the opportunity to tell them how this is changing". Professionals tended to look for their lead and examples from corporate management. For example, a Director of Nursing indicated that the CEO was the main change driver, that the project was very much his, and its success would reflect the degree to which people are converted to his philosophy.

\section{Leadership and change}

Both managers and professionals identified leadership as a necessary enabling influence 
throughout the organisation in the light of the need to disperse ownership of the vision and values. Both professionals and managers connected leadership with the new ideology or vision and values. Managers related it to the objective of the creation of a dynamic, transparent, and accountable organisation, and the professionals to the process of developing skills/competence and the provision of corporate exemplars. There were other views which stressed greater efficiency and effectiveness, or which accepted the inevitability of bureaucracy in a public service organisation.

The concept of leadership was not in common usage. Corporate accountability defined senior managers' generic responsibility as against others' general accountability parameters. Clinical responsibility related to the clinicians' definition and professional morale and practice influence to Directors of Nursing. They also connected leadership with service teams. Managerial leadership was systemic in nature. The professionals were more domain-specific, although they shared the organisational objective of leadership diffusion with managers. Their prototypes or idealised leader models varied. For managers, leadership was synonymous with change. One referred to "developing knowledge and skills in leadership and influencing, to contribute to the change agenda". The professionals' leader type - a credible attractor/influencer - had innate skills and possessed traits and attributes which gave credibility and which attracted and engaged others. For example, a Clinical Director suggested that, in his experience, respect and trust were key attributes of leadership in interdisciplinary teamwork. The more specific change orientation of the managerial prototype differentiated it from the non-specific influence (other than followership) of the professional prototype which was, presumably, contextually determined.

The managers' prototype was different from the norm and the associated personality traits were associated with change. They were: drive, energy, persistence and exceptional commitment to change as a constant in organisations. Maturity was also expected. The ability attributes were innovativeness, competence and cognisance (clarified structures and relationships).

Innate leadership in the professionals' model included attributes which were the result of parental influence, culture, and background. Confidence was a key trait, and the essence of good leadership. Ability attributes included a strong popular vision, significant knowledge, intelligence, and experience to motivate people in a professional service organisation where there were many intelligent people.

Both models shared the relational attribute of team motivator, but the professionals also linked it to effective performance. There were two contrasting professional perspectives on leadership relationships. Clinicians focused on the appropriate use of power and an awareness of its use by others. Directors of nursing emphasised empathy based on mutual trust and obligation. Both groups nevertheless, had a shared understanding of what attracts followers to leaders, namely, an affect of accessibility, loyalty, confidence, trust, and a capacity to engage and win over people.

\section{Leadership indications}

The presumption of leadership, its availability, and levels of autonomy or limitations were open to question. Managers, clinicians, and senior nurses were constrained by systemic, professional, and intrinsic factors which moderated their development as leaders. There 
were exogenous and endogenous influences. The nature of the public service, and the political system, technology, media and stakeholder expectations, combined with an inherited order which was centralist and administrative in orientation. Clinicians were suspicious of traditional management and not attracted by the reward system to become involved in management. They were protective of their clinical autonomy and time was prioritised to meet the demands of their clinical workload. They were also sensitive to peer pressure. Directors were cautious about the Department of Health because of previous experiences, and had a sense of past disempowerment due to hierarchical control within their own profession. They were described by some managers as advocates on behalf of their profession rather than as accountable service managers. Each group referred to a reluctance to take decisions, and an uncertainty about taking control and 'buying in' to local ownership. Clinicians attribute their reluctance to a lack of training and role models, although some have concerns about professional standards and the absence of clinician leaders. One lamented the lack of good role models, with the result he felt that "the way we're going, you are going to find it very difficult to get leadership at clinical level". Disempowerment in nursing was associated with a traditional hospital role which was described as subordinate, and whose members were required to be deferential to others. This created a lack of confidence in older nurses, and had enabled 'bullying' and an acceptance of their lot in silence in the past. The younger nurses however were not so tolerant, and would not accept adverse conditions. Managements' traditional image as administrators (i.e., a product of time and context) was also challenged by the influences of managerialism. The current management and the professions expected managers to provide change leadership, and to engage in the practice of modern management. A balance has to be struck in any case, in a clinician's view, between 'administrative' and 'clinical' leadership.

The change leader model was broadly reflected in some managers' change roles, traits, and relational attributes. As noted above, change leadership was primarily located in the CEO as the main initiator and driver. As one person commented, "(he is) the one with ultimate responsibility to see it (change) through". The CEO had previously instilled confidence in, and earned the loyalty, of senior staff in a major change project. He was supported by like-minded colleagues at corporate level whose commitment to change had also been demonstrated in their past experience. Two assistant CEOs shared the CEO's vision, enthusiasm, and confidence, based on competence, which inspired confidence in others. The CEO, as initiator, had good communication and interactive skills, and a sense of the people and the organisation. Although some could not relate to the vision that he communicated, others described it as inspirational, one commenting that "that language has actually fired me up, poetry-like language". The assistant CEOs were also seen as receptive, listening to staff, reflecting on what they said, and were interested in informing the vision, and in understanding the organisation from the bottom up.

In the professional domain, change leadership was associated with a young clinician who undertook a lead role in the area hospital executive, directors of nursing in mental health care, and senior professionals in child care. The directors were committed to major service change. It was indicated in their communication of the vision and values, in influencing beliefs, and in giving staff self-confidence when facing challenges. Those 
directors and some counterparts in acute care, had the confidence of staff because of their support and accessibility in anticipating and solving problems.

While many had good interpersonal skills, the abrasiveness of some clinicians, and the controlling behaviour of a director of nursing, were challenged by directors. There was also incongruity in some professionals' characteristics such as: having vision but lacking the energy to realise it; having drive without confidence; honesty irrespective of political sensitivity; and, demanding while encouraging initiative and responsibility. Intra-discipline relationships were emphasised in nursing, although there was a significant exception in a director's and her staff's perceived relationship with external colleagues and subordinates. Most of the directors valued mutual trust and obligation in their management-staff relationships. They demonstrated this by supporting their staff in problem situations. This attitude resonated at ward management level.

Managers' and professionals' matched expectations and indications of leadership provided an indicator of their congruity in primary (both have matched expectations and indications) and secondary (different expectations have matched indications) alignments. A consensus may be inferred from the primary set of attributes, namely, confidence, trust and teamwork and the secondary set, namely, (managers') energy, drive, enthusiasm, integrity and a participative style combined with (professionals') vision, respect, good interactive behaviour, awareness of people, and communications. Thus, the managers' 'change leader' and the professionals' 'attractor-influencer' may be differentiated by the formers' requirement of, for eaxample, energy. and an exceptional commitment to change the status quo. The professionals' prototype predicated followership in a sociotechnical context. They also attributed change influence to personal and peer influence, informal service leadership, and responsiveness to patients.

Systemic change leadership related primarily to the management domain, although there was some limited clinician involvement and change-ownership indicated by mental health directors of nursing and senior child care professionals' in respect of their services. The professional domain expected change leadership of managers.

\section{Style}

A change from an autocratic to a participative style was expected by sub-corporate managers so as to gain staff's commitment to the new ideology and to provide them with a guide in their leadership role.

There were different perceptions of the corporate style. Senior managers felt that there was a positive change to openness and empowerment, while general managers noted a tendency to be prescriptive and centralist. There were also different perceptions of the CEO's style as one senior manager described it as 'hands-on' and a general manager experienced it as 'hands-off'. Both domains believed that different styles were necessary to match situational needs and/or context. In acute care, where staff had strong opinions and degrees of power and authority, a more robust style, with appropriate systems, rules and standards, was seen as required. During the course of the study, a significant change in the dominant style was noted. Managers described it as open and empowering, and professionals as strong and visionary. Values and continuous learning were the new hallmarks of the organisation, and they had transformed the staff sense of being valued and the way they worked. 


\section{Approach to change}

The enabling objectives were intended to improve organisational cohesion and commitment to purpose with particular reference to relationships and ownership. A stakeholder approach was therefore envisaged, with multi-level/discipline input to reflect the ownership of change. Change leadership, however, appeared to be confined to senior management level.

Managers had different views of the pace of change, concerns about staff buying into change, and there were mid-managers who had difficulty in matching the values to service levels. Corporate communications used concepts and language which were not familiar to staff. Furthermore, mid-managers were perceived by senior managers at times to obstruct change, and they in turn were perceived to be prescriptive rather listening to understand other view points.

The enacted role of professionals in managing the process in Acute Care Services was limited. There was little evidence of action by some heads of discipline, and others who had participated in the regional meetings with management. Their local feedback was poor in content and process, because, as some explained, they did not have time. As a result, staff from acute care, in particular, who wanted to hear about the vision for the service, the reasons for change, and their role, were unclear on these matters. Various strategies were proposed by managers to improve the performance of the process. Although the professionals' contribution was rather confined, they wanted greater clarity, transparency, and effective communications. Actions and interventions to improve the process and its performance required greater input from local managers and heads of discipline. The drive for change, nevertheless, had to be sustained by senior managers, as there were continuing demands on everybody's time to deal with daily operational matters without any real increase in available resources.

\section{Managers' and professionals' agreement on key outcomes}

In due course, managers reported progress in relational development between senior management, clinicians, and the new structures. Stakeholder participation in processes gave them better understanding of change and systems, and it also improved their morale. The involvement of clinicians in management structures and general practitioners in hospital decision processes was reported by medical personnel. Nursing referred to the benefits of new structures and inter-disciplinary working. Ownership was enabled as a result of an open and facilitatory style. Managers referred to the CEO's record in delegation, and to a "very broad franchise in power and authority". Clinicians noted that staff was more empowered and enthusiastic to make decisions and take responsibility for the good of the organisation. They observed a positive change in the way people worked, and a greater sense of confidence and local control as a result of devolved authority. Directors and heads of discipline noted an emergent ownership in nursing which contrasted with the earlier reference to hierarchical control in that profession. Structural change included a better corporate level arrangement with decentralised line and functional management. Both professionals and managers referred to the positive impact of care group management and executive teams in all services, which enabled integrated management to support integrated care. These were facilitated by gradually engaging professions at all levels in management processes, such as the service planning/ 
budgeting cycle. Various activities effecting improved service quality, provision, and infrastructures were reported by the professional domain. External awards, published research, and customer-orientated initiatives were indicative of the emergence of a quality culture.

\section{Conclusion}

The exploration of alignment and variation in professionals' and managers' perspectives of their presumed determinants of effective change provide insight to their theoriesin-use. The multiple perspectives and methods combine to generate plausible and trustworthy findings, and support emergent theory. A linkage to existing literature that clarifies causes of variation in domain perspectives enhances the internal validity and theoretical level of theory building in this case study.

Domain differences (i.e., between managers and professionals), as explained by Edmondstone (1986), Kouse and Mico (1979), and Smith (1984), are a product of their primary orientations and norms. This study not only demonstrates the consequences of different professional socialisation processes and levels of autonomy, it also helps to clarify occupational differences in their organisational socialisation (Manning, 1977). That is evident in senior managements' accountability for the whole system, and a focus on population health and social gain; in other managers' and professionals' service and practice contexts and orientations. As a result of their implicit theories and leader prototypes, the professionals and mid-managers look to corporate leadership to sustain the change management project.

Professionals' and managers' common goal of leadership development and diffusion had different emphases. Managers sought a positive style to transform the core ideology, and the professionals required exemplars to transmit positive values. The differences in their domain prototypes of leadership reflected their contexts and primary orientations. The related objectives of improvement in relationships, ownership, structures, and the practice of management derived primarily from managers' inputs, and again illustrated their domain's organisational concerns, although they had support from senior nursing, and some clinicians and service groups. The latters' references to managers in their descriptions of leadership indications are generally positive, even though both domains' trait and task conceptualisations of leadership are traditional in their detail. Their role definitions are, however, more clearly differentiated as accountability in management, responsibility in medicine, and influencer of standards and morale in nursing for the benefit of patients' care. The concept of responsibility as accountability (public and clinical/professional), clinical leadership (position, professional, and personal) and influence (legal, legitimate, sapiential, and moral) rather than leadership as a social influence process (Yukl, 1989) provided an understanding of the domains' definitions of leadership in a complex system.

Domains Theory's (Kouse \& Mico, 1979) pre-occupation with interfaces and separate identities is modified in this case study which instead points to a predominance of intra-domain tensions. Those tensions illustrate hierarchical problems of status and distance within and across disciplines and their settings. They occur mainly in internal and external relationships associated with the Regional Acute Hospital, and include tensions attributed to hierarchical control in nursing (see, for example, Davies, 1985), 
in the nurse and non-nursing relationship, and in general practitioners' frustrations with their hospital- based colleagues. The latter concurs with Horobin's (1990) reference to the early dominance of hospital medicine, which left general practitioners in clientship to the hospital.

Managers also share problems of internal domain tensions, not unlike those experienced by their professional colleagues. Although there are initial reports of organisational distance in central-local relationships, there is no reference to conflict in the management and professionals' relationships. This contrasts with reports in the relevant literature (Broadbent \& Loughlin, 2002) which acknowledges the inevitability of conflict in medical-management relationships. There are, instead, acknowledgements of reciprocal engagements in projects and processes by some clinicians although others would like local managers to be more decisive.

Over time, the engagement of professionals in new management structures and processes became evident. They shared the experience of their international colleagues in adopting quasi-managerial roles (Halford \& Leonard, 1999; Kitchener, 2000). There is a comment on the perversity and paradox of empowerment in a bureaucracy which refers to senior managers unwillingness to "let go" and others" reluctance to "take on" responsibility. This is explained with regard to the nature of public accountability and inter-strata confidence. It nevertheless represents a barrier to change, in spite of the "broad franchise in power and authority" as a result of the CEO's vision, style, and approach to change. Both domains express their limitations and constraints in developing their leadership capacity with reference to systemic, professional, and intrinsic factors. This has resonance in Berwick's (1989) explanation of clinicians' failure to provide leadership in quality improvement programmes in terms of time, tradition, territory, and trust.

Variation in aspects of professionals' and managers' views of purpose, roles and leadership expectations and indications equates with a systemic orientation in senior management as against a more domain-specific orientation from the professions. This extends to some managers' pre-occupations with routine responsibility. At one level, this provides essential variety so as to maintain the enterprise in transition. From another perspective, different types and levels of leadership are required, but they must be connected, even though varied as to focus, context, and primary orientation (Jacobs \& Jaques, 1987; Osborn, Hunt, \& Jauch, 2002).

Management and professional perspectives on the main outcomes of the change process relate to the attributed aim and its enabling objectives. Both agree on progress. The professionals are more explicit in their reports of positive experiences arising from the new style and approach in the organisation. They refer to a transformation which affected how people work, their sense of being valued, and the benefits of the new structures and various service developments. Managers share their traditional activity domain with professional colleagues who participate in organisational processes that support and influence the nature and quality of care. That is the key alignment in their shared purpose.

Concepts and knowledge, which are relevant to theory and practice, are best grounded in context, particularly if the contexts are complex adaptive systems presenting as institutions of the State. Variation and alignment are necessary, as variety and diversity 
enrich opportunities for growth and development in messy real world situations. However, the inevitability of paradox, uncertainty, and ambiguity is present, even in role-compliant bureaucracies. Organisational cohesion is dependent on shared values, beliefs and connectedness, and not on conventional notions of control and controllability or leadership. What is problematic (and may be explained by further research on interand intra-domain relationships and connectivity) is the management of the activities of certain professions by other disciplines, and the need for duality and pluralism in accountability and competencies in complex systems.

This paper would not be complete without a final word on the reflexive methodology employed. The choice of topic and title of the overall project is indicative of the CEO/researcher's approach in adopting an alternative strategy to examining leadership in context. A qualitative methodology went beyond a preoccupation with certain variables associated with leadership, and facilitated enquiry into participants' meanings and interpretive systems to gain insight into their embedded explanations and understandings. This recognised the problems of managerial control in complex adaptive systems such as healthcare organisations, and the use of totalising concepts such as leadership that limit the possibility of alternative explanations of what is occurring.

Participation in research in any role can change the nature of the phenomenon under investigation. In the case of a $\mathrm{CEO} /$ researcher there were potentially greater challenges in addressing reflexivity, subjectivity, and intersubjectivity. The change programme included concepts of organisational learning and the creation of a learning organisation to support reflective research active practitioners in becoming more evidence-based in their practice and in the dissemination of outputs of research enterprises. This was compatible with the adoption of an internal researcher role by the $\mathrm{CEO}$, and had the resonance of attempting to be the change one wished the organisation to become! References to leadership as an imposition of a version of social reality were avoided in so far as possible. This facilitated the exploration of a full range of internal influencers and influences that participants attributed to change agency and agents. At the same time, the broader scope of the project created more demands in the comparative data analysis stage.

A major challenge was the need for constant vigilance in managing one's own subjectivity while exploring and being attentive to others' alternative views and explanations of a shared reality. At the same time, like-minded managers' and professionals' intersubjective acceptance of norms in expectations and understandings necessitated greater reflexivity than in contrary positions. Avoidance of contradiction or affirmation both verbal and non-verbal was essential in all individual and group engagements that had the primary objective of data collection. In group contexts, participating managerial colleagues interacted with other participants in the normal way. The research role limited the nature of the CEO's participation to non-directive engagement.

Reflection on the experience as $\mathrm{CEO} /$ researcher suggests the need for early identification of compatibilities across the worlds of research and practice. Otherwise endless cul de sacs that may be avoidable are entered. Expert guidance is a must in embarking on such enterprises, as the research becomes both an individual and corporate enterprise. Legitimacy and relevance is not usually contested. However, rigour in 
data quality in collection and analysis is the standard. The concurrent, confounding, and competing role issues overtake on waves of precedence and urgency creating postponement and discontinuity. Inevitably, role duality has its own inherent tensions!

\section{Acknowledgments}

My thanks to the anonymous reviewers for their feedback on an earlier version of this paper and to John McCarthy for his expert guidance in providing this final version.

\section{References}

Berwick, D.M. (1989). Continuous improvement as an ideal in health care. New England Journal of Medicine, 320, 53-56.

Broadbent, J., \& Loughlin, R. (2002) Public service professionals and the new public management: Control of the professions in the public services. In K. Mc Laughlin, S.P. Osborn, \& E. Ferlie (Eds.), New public management: Current trends and future prospects (pp. 95-108). London: Routledge.

Clifford, J. (1983). On ethnographic authority. Representations, 2, 118-146.

Coghlan, D., \& Brannick, T. (2001). Doing action research in your own organisation. London: Sage.

Davies, C. (1985). Professionals in bureaucracies: The conflict thesis revisited. In R. Dingwell \& P. Lewis (Eds.), The sociology of the professions (pp. 177-194). Basingstoke, UK: Macmillan Press Ltd.

Denzin, N.K., \& Lincoln, Y.S. (1998). Strategies of qualitative enquiry. London: Sage.

Dingwall, R. (1980). Ethics and ethnography. Sociological Review, 28, 871.

Edmondstone, J. (1986). If you're not the woodcutter, what are you doing with the axe? Health Services Manpower Review, 12, 8-12.

Etherington, K. (2004). Becoming a reflexive researcher. London: Jessica Kingsley Publishers.

Etzioni, A. (Ed.) (1969). Semi-professions and their organisations. New York: Free Press.

Ferlie, E., Ashbourner, L., Fitzgerald, L., \& Pettigrew, A. (1996). The new public management in practice. Buckingham, UK: Open University Press.

Flynn, N., \& Strehl, F. (Eds.) (1996). Public sector management in Europe. London: Prentice Hall/Harvester Wheatsheaf.

Gouldner, A.W. (1957). Cosmopolitans and locals: Toward an analysis of latent social roles - I. Administrative Science Quarterly, 2, 281-306.

Gouldner, A.W. (1958). Cosmopolitans and locals: Toward an analysis of latent social roles - II. Administrative Science Quarterly, 2, 444-480.

Halford, S., \& Leonard, P. (1999). New identities? Professionalism, managerialism and the construction of self. In M. Exworthy \& S. Halford (Eds.), Professionals and the new managerialism in the public sector (pp. 102-121). Buckingham, UK: Open University Press.

Hearing, S., Dent, T., Swann, J., Gunaratna, I., McLellan, I., \& Ikidde, U. (1999). Maximising the contribution doctors make to NHS management. Health Services Management Research, 12, 227-231. 
Homa, P. (1998). Re-engineering the Leicester Royal Infirmary health care process. Unpublished DBA thesis. Henley Management College and Brunel University.

Horobin, G. (1990). Professional mystery: The maintenance of charisma in general medical practice. In R. Dingwall \& P. Lewis (Eds.), The sociology of the professions (pp. 84-105). Basingstoke, UK: Macmillan Press Ltd.

Jacobs, T.O., \& Jaques, E. (1987). Leadership in complex systems. In J. Zeidner (Ed.), Human productivity enhancement: Organisations, personnel and decision-making (Vol. 2, pp. 7-65). New York: Praeger.

Johnson, M. (1985). Professional careers and biographies. In R. Dingwell \& P. Lewis (Eds.), The sociology of the professions (pp. 242-262). Basingstoke, UK: Macmillan Press Ltd.

Kitchener, M. (2000). The 'bureaucratization' of professional roles: The case of clinical directors in UK hospitals. Organisation, 7, 129-154.

Kouse, J., \& Mico, P. (1979). Domain theory: An introduction to organisational behaviour in human service organisations. Journal of Applied Behavioural Science, 15, 44969.

Krim, R. (1988). Managing to learn: Action inquiry in City Hall. In P. Reason (Ed.) Human inquiry in action (pp. 144-162). London: Sage.

Lorentzon, M. (1990). Professional status and managerial tasks: Famine service ideology in British nursing and social work. In P. Abbott \& C. Wallace (Eds.), The sociology of the caring professions (pp. 53-66). Basingstoke, UK: The Falmer Press.

Manning, P.K. (1977). Talking and becoming: A view of organization socialization. In R.L. Blankenship (Ed.), Colleagues in organisation: The social construction of professional work (pp.181-205). London: Wiley \& Sons.

Mintzberg, H. (1983). Structure in fives: Designing effective organisations. Englewood Cliffs, NJ: Prentice Hall.

Osborn, R.N., Hunt, J.G., \& Jauch, L.R. (2002). Toward a contextual theory of leadership. The Leadership Quarterly, 13, 797-837.

Partington, D. (2000). Building grounded theories of management action. British Journal of Management, 11, 91-102.

Pettigrew, A., Ferlie, E., \& McKee, L. (1992). Shaping strategic change. London: Sage.

Saltman, R.B., \& Figueras, J. (1997). European health care reform: Analysis of current strategies. WHO Regional Publications: European Series No. 72.

Sheaf, R. (2000). The new institutional economics: An application to public service governance design in UK primary health care. Public Management, 2, 441-455.

Shipper, F., Pearson, D.A., \& Singer, D. (1998). A study and comparative analysis of effective and ineffective leadership skills of physician and non-physician health care administrators. Health Services Management Research, 11, 124-135.

Shortell, S.M., Morrison, E.M., \& Robbins, S. (1985). Strategy making in health care organisations. A framework and agenda for research. Medical Care Review, 42, $219-$ 266.

Smith, G. (1984). Towards an organisational theory for the NHS? Health Service Manpower Review, 19, 3-7.

Strauss, A.L., \& Corbin, J.M. (1990). Basics of qualitative research: Grounded theory 
procedures and techniques. Beverly Hills, CA: Sage.

Taylor, R.J., \& Taylor, S.B. (1994). The AUPHA manual of health services management. Gaithersburg, MD: Aspen Publishers, Inc.

Thorne, M.L. (2002). Colonizing the new world of NHS management: The shifting power of professionals. Health Services Management Research, 15, 14-26.

Yukl, G. (1998). Leadership in organisations. London: Prentice-Hall Intl. 